\title{
What can we do to help Australians die the way they want to?
}

\section{A different service mix could better meet end-of-life care needs for little additional cost}

ustralians are not dying as they would wish. Surveys consistently show that between $60 \%$ and $70 \%$ of Australians would prefer to die at home, and that residential care facilities are their least preferred option. ${ }^{1}$

Dignity, control and privacy are important for a good death. Choice over who will be present, where people will die and what services they will get, matters.

People want their symptoms to be well managed, and they want personal, social and psychological support. It is important to have the opportunity to say goodbye and leave when it is time to go without pointlessly prolonging life. ${ }^{2}$

\section{"dying is not discussed, and we are not taking the opportunity to help people plan and prepare for a good death"}

But dying is now highly institutionalised. Over the past century, the proportion of deaths at home has declined and that of deaths in hospitals and residential aged care has increased. Today only about $14 \%$ of people die at home in Australia. Fifty-four per cent die in hospitals and $32 \%$ in residential care. Home and other non-institutional deaths are about half as prevalent in Australia as they are in New Zealand, the United States, Ireland and France. ${ }^{3}$

Paradoxically, the likelihood and timing of death is now more predictable and there is more opportunity and time to prepare for death because people are now much more likely to die from chronic disease in old age. But dying is not discussed, and we are not taking the opportunity to help people plan and prepare for a good death. As a result, many experience a disconnected, confusing and distressing array of services, interventions and relationships with health professionals when they are dying.

\section{Having the conversation}

When asked, most people have clear preferences for the care they want at the end of their life. But these preferences are rarely articulated, and they are not supported by the open, systematic conversations that are needed to ensure effective end-of-life care plans. Instead there is an unspoken faith that science and medicine can put off the inevitability of death., ${ }^{4,5}$

As a result, intrusive and burdensome interventions, including emergency and hospital admissions and

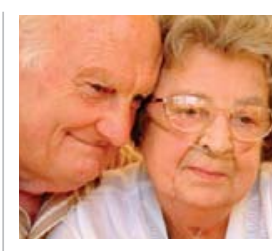

intensive care often continue when there is little point. Palliative care is not discussed, offered or provided, and services are variable, inconsistent and fragmented, particularly for support at home and in the community. Women, single people, older people and Indigenous people die in hospital at a higher rate than the general population. People with culturally and linguistically diverse backgrounds and those from rural communities are more likely to find access to services more difficult. ${ }^{6}$ These issues will become more prominent in public policy as the baby boomers age and the crude death rate doubles over the next 25 years. ${ }^{7}$

Four reforms would facilitate a good death. First, we need more public discussions about the limits of health care as death approaches, and what we want for the end of life. Second, the public discourse needs to be translated into personal choices. People need to plan better to ensure that their desires for the end of life are complied with. Third, we need to ensure that if patients have expressed wishes about the care they want at end of life, those wishes are followed. Fourth, services for those dying of chronic illness need to be reoriented so that they focus more on people's wishes to die at home and in homelike settings, rather than in institutions.

\section{Encouraging people to plan for death}

Failure to talk about and plan for death in advance is one of the most significant obstacles to improving the quality of dying. Having these conversations and making these plans is not easy. When death is near and the quality of life is low, it is hard to know how far to pursue treatment, especially when the treatment is stressful, intrusive and likely to further reduce quality of life. Decision making is even more stressful if there has been no previous discussion about treatment preferences so that choices must be made in the pressure cooker environment of a hospital.

Public education programs have been used with great success in other parts of the health sector to educate the public and set the preconditions for policy change.

Hal Swerissen BAppSc, BA(Hons), MAppPsych

Stephen J Duckett PhD, DSc, FASSA Health Program, Grattan Institute, Melbourne, VIC.

stephen.duckett@ grattan.edu.au

doi: 10.5694/mjal4.01580
People could be encouraged by a public education campaign to consider and discuss their end-of-life preferences with their families and appropriate health care professionals, and document them in advance care plans. A national public education campaign would focus on encouraging people to discuss their preferences and choices for end-of-life care with health professionals, including general practitioners.

We estimate that a national campaign of 12 to 18 months' duration that encompassed mass media, public relations, online and digital media, direct 
marketing and education campaigns would cost $\$ 10$ million.

There are now well developed and effective approaches for systematic discussion of end-of-life treatment and care and the development of advance care plans. Yet much greater encouragement and incentives are required to ensure that those plans are much more widely implemented. ${ }^{8}$

Health professionals are in the best position to initiate end-of-life discussions. However, they must shift their focus from prevention, cure and rehabilitation at appropriate points in time if these conversations are to occur. It is therefore important that it becomes normal and expected practice for health professionals to discuss and plan for end of life with their patients when it is appropriate. End-of-life plans are personal expressions. They should set out personal choices about the type and level of intervention a person wants: from aggressive intervention through to less interventionist and palliative care.

Initiating discussions about intentions at the end of life can be hard so we propose that "trigger points" for mandatory discussions about intentions be introduced:

- during health assessments for people aged over 75 years;

- for all residents of aged care facilities and for highneeds recipients of home-based care packages as part of assessment and care planning; and

- for all hospital inpatients who are likely to die in the next 12 months.

Advance care plans are important, but are not in themselves enough to ensure that the wishes of dying people are met and that end-of-life care is improved. Additional measures need to be in place to ensure that plans are implemented as part of systematic and patient-centred end-of-life care.

\section{What is needed for good end-of-life care?}

Good care at the end of life is coordinated and multidisciplinary. Yet this is difficult in Australia's largely siloed health system. As well, people receiving palliative care often transfer between health care settings, such as home, general practice, specialist medical, outpatient subacute, residential care and hospital.

It is essential to improve the coordination of endof-life care, as hard as that is to do in a fragmented system. Effective strategies include the use of care coordination, case conferencing and team discussion. People who are dying often need a well qualified and authoritative health professional to act as an advocate for them to get the care they need.

Legislative frameworks and guidelines for advance care plans need to change. They should include clear mechanisms for assigning specific responsibility to health care professionals to coordinate and implement plans when people enter end-of-life care.
If the wishes of most Australians to die at home are to be met, end-of-life care will have to change. More support for dying at home will be required.

Carers say they do not get the support they need from partners, family or health professionals. The end of life does not follow a common trajectory. Often patients who have been discharged home will have a crisis episode that carers have to manage. The inability to manage a crisis at home is one of the main reasons that people at the end of their life are admitted to hospitals via emergency departments. It is not surprising that carers struggle to cope: only $13 \%-18 \%$ of carers report that they could access services such as health professionals, community organisations and government services in a crisis. ${ }^{9}$

It is clear that community-based palliative care can reduce the burden on carers and significantly increase the proportion of people who are able to die at home. But this will require a significant increase in the availability of community-based palliative care. Packages to support dying at home include coordination, nursing and personal care, specialist medical services where required, carer support and respite.

The number of people dying at home would have to double to reach $30 \%$ of all deaths, a level comparable to Korea, Singapore, Ireland, France, Austria, Croatia, the United States, Cyprus and New Zealand. To support these people with home-based care packages would require 39000 more packages per year to be made available for those who are likely to die within the next 3 months. ${ }^{3}$

\section{What will it cost?}

We estimate that the average cost of community palliative care packages is about $\$ 6000$ for the last 3 months of life. Extending the availability of community packages to enable $30 \%$ of Australians to die at home would require an additional investment of $\$ 241$ million. $^{10}$

Increased home and community care for the dying is likely to reduce the demand on hospital and residential aged care services. If that demand declined in proportion to the increased number of people dying in the community, we estimate that costs would reduce by $\$ 324$ million in acute and subacute hospital sectors and $\$ 275$ million in residential care institutions for an overall saving of $\$ 50$ million.

Taking into account the additional estimated cost of community-based palliative care packages and the savings in residential and hospital services, a net cost of $\$ 84$ million is estimated as a result of the increase in community-based support for people who are dying.

Competing interests: No relevant disclosures.

Provenance: Commissioned; not externally peer reviewed. 
1 Foreman LM, Hunt RW, Luke CG, Roder DM. Factors predictive of preferred place of death in the general population of South Australia. Palliat Med 2006; 20: 447-453.

2 Smith R. A good death. An important aim for health services and for us all. BMJ 2000; 320: 129-130.

3 Broad JB, Gott M, Kim H, et al. Where do people die? An international comparison of the percentage of deaths occurring in hospital and residential care settings in 45 populations, using published and available statistics. Int J Public Health 2013; 58: 257-267.

4 Higginson IJ, Hales S, Koffman J, et al. Time to get it right: are preferences for place of death more stable than we think? Palliat Med 2010; 24: 352-353.

5 Ashby MA, Kellehear A, Stoffell BF. Resolving conflict in endof-life care. Med J Aust 2005; 183: 230-231.

6 Senate Community Affairs References Committee. Palliative care in Australia. Canberra: Commonwealth of Australia,
2012. http://www.aph.gov.au/Parliamentary_Business/ Committees/Senate/Community_Affairs/Completed_ inquiries/2010-13/palliativecare/report/index (accessed Dec 2014).

7 Australian Bureau of Statistics. Population projections, Australia, 2012 (base) to 2101. Canberra: ABS, 2013. (ABS Cat. No. 3222.0.) http://www.abs.gov.au/AUSSTATS/abs@.nsf/ DetailsPage/3222.02012\%20\%28base\%29\%20to\%20 2101?OpenDocument (accessed Dec 2014).

8 Detering KM, Hancock AD, Reade MC, Silvester W. The impact of advance care planning on end of life care in elderly patients: randomised controlled trial. BMJ 2010; 340: c1345.

9 Cummins RA, Hughes J, Tomyn A, et al. Wellbeing of Australians: carer health and wellbeing. Melbourne: Deakin University, Carers Australia and Australian Unity, 2007.

10 Swerissen H, Duckett S. Dying well. Melbourne: Grattan Institute, 2014. http://grattan.edu.au/wp-content/ uploads/2014/09/815-dying-well.pdf (accessed Dec 2014). 